\title{
Maintenance of Respiratory Control in Mitochondria after Rate Zonal Centrifugation
}

\author{
M. J. Dimino* and F. L. Hoch \\ The Departments of Biological Chemistry and Internal Medicine, \\ The University of Michigan Medical School, Ann Arbor, Michigan 48104 \\ Received 30 June 1972 \\ Abstract \\ The respiratory control of rat liver mitochondria is lost when they \\ are subjected to rate zonal centrifugation in a sucrose gradient $(8.0 \%$ \\ to $46.6 \%, w / w)$ at values for $\omega^{2} t$ necessary for resolution. High \\ sucrose concentration and high $\omega^{2} \mathrm{t}$ are both responsible. Respiratory \\ control can be maintained in iso-osmotic Ficoll $+8.3 \%$ sucrose \\ media, and after zonal centrifugation in such media at values of $\omega^{2} t$ \\ sufficient for resolution.
}

\section{Introduction}

We have observed that rat liver mitochondria prepared by the usual differential centrifugation in $8.3 \%(0.25 \mathrm{M})$ sucrose lose respiratory control during a subsequent rate zonal centrifugation through a sucrose gradient $(8 \% \mathrm{w} / \mathrm{w}$ to $46.6 \%)$. Little reference has been made to changes in mitochondrial oxidative phosphorylation after zonal centrifugations, although "damage" has been recognized from electron micrographs and from the solubilizations of enzymes [1, 2]. To extend the usefulness of the zonal centrifugation method, we have studied the effects of suspending medium and of force on oxidative phosphorylation, and find that respiratory control can be preserved in an iso-osmotic Ficoll gradient at low rotor speeds sufficient for resolution.

\section{Materials and Methods}

Rat liver was pulped and then homogenized in $8.3 \%$ sucrose, $\mathrm{pH} 7.4$. Heavy debris and cells were removed by spinning twice at $600 \mathrm{~g}_{\mathrm{av}}$ for $5 \mathrm{~min}$ in a refrigerated centrifuge. A mitochondrial fraction was

* NIH Postdoctoral Fellow

Copyright () 1972. Plenum Publishing Company Limited. No part of this publication may be reproduced, stored in a retrieval system, or transmitted, in any form or by any means, electronic, mechanical, photocopying, microfilming, recording or otherwise, without written permission of Plenum Publishing Company Limited. 
sedimented at $13,500 \mathrm{~g}_{\text {av }}$ for $20 \mathrm{~min}$ in a $\cdot 30$ rotor in a refrigerated ultracentrifuge (Spinco Division, Beckman Instruments). The mitochondrial pellet was resuspended in $0.25 \mathrm{M}$ sucrose alone, or in sucrose with $5 \%$ or $15 \%(\mathrm{w} / \mathrm{v})$ Ficoll (a synthetic high copolymer of sucrose and epichlorohydrin, obtained from Pharmacia Fine Chemicals, Inc.), pH 7.4.

Rate zonal centrifugation was then performed according to Price [3]. All mitochondrial samples were adjusted to $8.0 \%$ sucrose and introduced into a Ti-14 zonal rotor (Beckman). Sucrose gradients ran from $8.0 \%(\mathrm{w} / \mathrm{w})$ to $46.6 \%$. Ficoll gradients were from $5 \%(\mathrm{w} / \mathrm{v})$ to $12 \%$, and the presence of $8.3 \%$ sucrose throughout the gradient maintained an iso-osmotic condition. Gradient concentrations were determined with an Abbe refractometer.

Oxygen consumption was determined polarographically (Oxygraph, Gilson Medical Electronics). The reaction mixture of $3 \mathrm{ml}$ volume, $\mathrm{pH} 7.4,25^{\circ} \mathrm{C}$, contained $0.25 \mathrm{M}$ sucrose, $7.4 \mathrm{mM} \mathrm{KCl}, 7.4 \mathrm{mM}$ Tris, $3.0 \mathrm{mM}$ potassium mono- and dihydrogen phosphates, $0.16 \mathrm{mM}$ EDTA, $2.7 \mathrm{mM}$ succinate or glutamate; $58 \mu \mathrm{M}$ ADP was added to measure respiratory control (the ratio, State 3 : State 4 respiration) and phosphorylation (the ADP : 0 ratio).

\section{Results}

Mitochondrial pellets prepared by differential centrifugation have a respiratory control ratio of 2.75 (substrate, succinate) when suspended in $8.3 \%$ sucrose (Table I). Suspension in $40 \%$ sucrose abolishes respiratory control, but suspension in $7.5 \%$ Ficoll $+8.3 \%$ sucrose depresses respiratory control only slightly, by $-18 \%$. Sucrose obtained from commercial sources usually contains calcium in significant amounts [4], and concentrated sucrose might thus abolish respiratory control via massive $\mathrm{Ca}^{++}$-loading of the mitochondria [5]. However, this does not seem to be the case, because mitochondrial pellets suspended in $40 \%$ sucrose containing 1-10 mM EDTA, to lower free $\left[\mathrm{Ca}^{++}\right]$, have no respiratory control. Nor do our $40 \%$ sucrose solutions contain enough calcium $(0.7 \mathrm{mM})$ to produce massive loading. The mitochondria in such solutions are exposed to 0.1 to $0.2 \mu$ moles of $\mathrm{Ca}^{++}$per $\mathrm{mg}$ protein; approximately $100 \mu$ moles of $\mathrm{Ca}^{++}$per $\mathrm{mg}$ are required to produce even limited loading [6], which does not affect respiratory control. The concentrated sucrose solutions thus probably lower respiratory control through their high osmotic pressures, whereas the Ficoll-sucrose medium is iso-osmotic.

When mitochondria, suspended in $8.0 \%$ sucrose, are separated by zonal centrifugation through a sucrose gradient, their capacity for 
TABLE I. Effects of $\omega^{2} t$ and suspending medium on respiratory control in rat liver mitochondria

\begin{tabular}{cccc}
\hline & \multicolumn{3}{c}{ Respiratory control } \\
\cline { 2 - 4 } & $\begin{array}{c}\text { in } 8.3 \% \\
\text { Mitochondria isolated by: }\end{array}$ & $\begin{array}{c}\text { in } 40 \% \\
\text { Sucrose }\end{array}$ & $\begin{array}{c}\text { in } 7.5 \% \text { Ficoll } \\
+8.3 \% \text { Sucrose }\end{array}$ \\
\hline $\begin{array}{c}\text { Differential centrifugation } \\
\left(13,500 \text { gav }_{\text {a }} 20 \mathrm{~m}\right)\end{array}$ & 2.75 & 1.00 & 2.24 \\
Rate zonal centrifugation & & & \\
$\omega^{2} \mathrm{t}\left(\times 10^{-9}\right)$ & & & \\
12.5 & & 1.00 & \\
1.97 & 1.00 & 1.00 & 1.00 \\
1.31 & & & 2.61 \\
0.164 & & & \\
0.082 & 2.08 & & \\
\hline
\end{tabular}

Mitochondrial pellets were prepared by differential centrifugation, suspended in one of three media shown, and assayed for respiratory control (substrate, $2.7 \mathrm{mM}$ succinate). Mitochondrial samples also were prepared, suspended in $8.3 \%$ sucrose, and subjected to rate zonal centrifugation through a sucrose gradient $(8 \%$ to $46.6 \%)$ or an iso-osmotic sucrose-Ficoll gradient ( $5 \%$ to $12 \%)$. Fractions were obtained at the specified concentrations of medium after sedimentation corresponding to the given values of $\omega^{2} t$, and assayed for respiratory control.

respiratory control also depends on the $\omega^{2} t$ value (Table I). At $\omega^{2} \mathrm{t}$ $=12.5 \times 10^{9}(25,000 \mathrm{rpm} \times 30 \mathrm{~m})$ or $1.97 \times 10^{9}(10,000 \mathrm{rpm} \times 30 \mathrm{~m})$, which are usual values for resolving mitochondria [3], respiratory control is abolished in the fractions containing $8.3 \%$ or $40 \%$ sucrose. At low $\omega^{2} t, 0.082 \times 10^{9}, 75 \%$ of the original respiratory control is preserved in the $8.3 \%$ sucrose fractions; however, this low force is not sufficient to migrate any mitochondria to the heavy end of the sucrose gradient. In the iso-osmotic sucrose-Ficoll gradient fractions at the $7.5 \%$ Ficoll level have no respiratory control at $\omega^{2} \mathrm{t}=1.31 \times 10^{9}(10,000 \mathrm{rpm}$ $\times 10 \mathrm{~m})$, but show excellent respiratory control at $\omega^{2} \mathrm{t}=0.164 \times 10^{9}$ $(5,000 \mathrm{rpm} \times 5 \mathrm{~m})$. At the latter force-time value, the mitochondria maintain control for at least $1 \frac{1}{2} \mathrm{~h}$; thereafter respiration in State 4 increases and the ADP : $O$ ratio decreases.

Suspending mitochondria in $5 \%$ or $15 \%$ Ficoll $+8.3 \%$ sucrose has little effect (ca. $-20 \%$ ) on respiratory control or phosphorylation, with either succinate or glutamate as substrate (Table II).

\section{Discussion}

High concentrations of sucrose depress mitochondrial respiratory control, probably due to the incident osmotic stress [7]. Ficoll, with 
TABLE II. Effects of Ficoll on oxidative phosphorylation in rat liver mitochondria.

\begin{tabular}{llcc}
\hline $\begin{array}{c}\text { Resuspending } \\
\text { medium: }\end{array}$ & $\begin{array}{c}\text { Substrate } \\
\text { used: }\end{array}$ & $\begin{array}{c}\text { Respiratory } \\
\text { control }\end{array}$ & ADP : O \\
\hline 1. $0.25 \mathrm{M}$ sucrose & succinate & 2.39 & 1.14 \\
& glutamate & 2.24 & 2.40 \\
2. 5\% Ficoll + & succinate & 1.79 & 1.20 \\
0.25 M sucrose & glutamate & 2.90 & 2.10 \\
3. 15\% Ficoll + & succinate & 2.06 & 0.95 \\
0.25 M sucrose & glutamate & 2.24 & 1.87 \\
\hline
\end{tabular}

Mitochondria were isolated by differential centrifugation at $13,500 \mathrm{gav} \times 20 \mathrm{~min}$ and resuspended in $0.25 \mathrm{M}$ sucrose alone or with $5 \%$ or $15 \%(\mathrm{w} / \mathrm{v})$ Ficoll. Oxidative phosphorylation was measured as described in Methods.

a molecular weight of about 400,000 , is relatively inert osmotically, and has minor effects on respiratory control. Although Ficoll gradients at relatively high $\omega^{2} \bar{t}$ are reported to depress glutamate dehydrogenase activity in rat liver mitochondria [8], under the conditions shown here concentrations of Ficoll up to $15 \%$ do not change $\mathrm{O}_{2}$ consumption during glutamate oxidation, although they slightly decrease phosphorylative efficiency. To maintain respiratory control, it is also necessary to use lower centrifugal forces with either a Ficoll or a sucrose gradient. With sucrose, a gradient sufficiently concentrated for resolution cannot be used without introducing osmotic stress. Iso-osmotic Ficoll gradients at low speeds seem useful in resolving functionally intact rat liver mitochondria by zonal centrifugation.

\section{Acknowledgements}

This work was supported by grants from the NIH (AM13564) and from The John A. Hartford Foundation.

\section{References}

1. C. de Duve, J. Cell Biol., 50 (1971) 20.

2. R. Wattiaux, S. Wattiaux-DeConinch, and M-F. Ronveaux-Dupal, Eur. J. Biochem., 22 (1971) 31.

3. C. A. Price, in "Manometric Techniques", W. W. Umbreit, R. H. Burris and J. F. Stauffer (Burgess Pub. Co., Minneapolis) 5th ed. in press.

4. D. W. Allmann, T. Wakabayashi, E. F. Korman, and D. E. Green, J. Bioenergetics 1 (1970) 73.

5. V. R. Potter, J. Biol. Chem., 169 (1947) 17. 
6. E. Carafoli and A. L. Lehninger, in "Methods in Enzymology", Vol. X, eds. R. W. Estabrook and M. E. Pullman, Academic Press, New York (1967) 745. 7. A. L. Lehninger, Physiol. Rev., 42 (1962) 467.

8. C. V. Lusena and F. Depocas, Can. J. Biochem. 44 (1966) 497.

Note added in proof:

Observations that high sucrose concentrations suppress the transport of inorganic phosphate ions across the mitochondrial membranes (D. E. Green, personal communication) provide an alternative explanation for the depression of phosphorylation. 